\title{
Prevalence of Undernutrition and Associated Factors among Children Aged 6- 59 Months in Bishoftu Town, Oromia Region, Ethiopia
}

\author{
Abebe Haile* and Melaku Abebaw \\ College Development Studies, Centre for Food Security Studies, Addis Ababa University, Addis Ababa, Ethiopia
}

Correspondence should be addressed to Abebe Haile, abebe.haile@gmail.com ; abebe.haile@aau.edu.et

Received: February 14, 2019; Accepted: March 11, 2020; Published: March 18, 2020

\begin{abstract}
Malnutrition is decreasing during the two-decade but still in a major public health problem in the world especially in developing countries including Ethiopia. The study was aimed to assess the prevalence of malnutrition and associated factors among children of aged 6 months - 59 months of Bishoftu town, Oromia region. Community based cross-sectional design was employed in the randomly selected five kebele. The sample size was determined by using single population proportion formula then adjusted by finite population correction factor to draw the final 410 sample children and then allocated proportionally to each Kebele in the town. The survey was conducted using standard procedures developed questionnaires with experienced enumerators. Anthropometric measurement was used to collect height, weight and MUAC following the standard measurement tools and procedures. Information was entered into Epi-Data version 3.1 and anthropometric measurements were converted into $\mathrm{Z}$ scores by WHO Anthro version 3.2.2., 2011 software. Then exported to STATA 13 and analyzed using descriptive statistics and inferential statistics. The result revealed that the prevalence of overall malnutrition was (46.1\%); specifically, stunting was (16.1\%), underweight $(22.6 \%)$ and wasting $(7.4 \%)$. Bivariate and multivariate logistic regression model was employed to analyze prevalence of child malnutrition. The result of multivariate model revealed that Family size, Birth interval, Child age and Frequency of breast feed as significant determinants for wasting. While for stunting, family size, level of mother's education, birth order, currently breast feeding, exclusive breast feeding and monthly income were found as statistically significant $(\mathrm{p}<0.05)$ determinants of child malnutrition. Additionally, age of child and household who hadn't got advice and visited by health extension workers were more than five as likely to be underweight compared to those who are frequently advised? Thus, the studied households need continues training, awareness creation activities, special attention for child and maternal healthcare services by the Health Office and other practitioners in different income generating activities to improve child nutrition.
\end{abstract}

\section{KEYWORDS}

Malnutrition; Children age 6-59 months; Bishoftu; Determinant factors; Oromia

\section{INTRODUCTION}

\section{Background of the study}

Malnutrition is a major public health problem in the world rates are dropping but 159 million children around the especially in Sub Saharan countries. Stunning and wasting world are still affected [1]. Malnutrition is attributed to Citation: Abebe Haile, Prevalence of Undernutrition and Associated Factors among Children Aged 6-59 Months in Bishoftu Town, Oromia Region, Ethiopia. Food Proc Nutr Sci 1(1): 8-24.

(C)2020 The Authors. Published by TRIDHA Scholars. 
one third of under-five death, in the first five years of life which is preventable by economic growth [2]. Malnutrition remains one of the most common causes of morbidity and mortality among children throughout the world. It has been responsible, directly or indirectly for $60 \%$ of the 10.9 million deaths annually among children fewer than five and two-thirds of these deaths are often associated with inappropriate feeding practices [3]. Globally an estimated 101 million children below five years of age are underweight (16\%). There were 59 million in South Asia; the prevalence was the highest which was $33 \%$, followed by Sub-Saharan Africa while 30 million were in sub-Saharan Africa (21\%). Child malnutrition affects academic performance and physical and mental development throughout their lives [2]. Underfive malnutrition is an indicator of one's countries health status as well as economic conditions [4]. Malnutrition among children is a critical problem because its effects are long lasting and go beyond childhood. It has both short and long term consequences [5]. Malnutrition, especially under five children stills a devastating problem in developing countries, especially in sub-Saharan Africa, including Ethiopia [6]. Stunting, wasting, and underweight are among those anthropometric indicators which are commonly used to measure malnutrition of under five children. Underweight, low weight-for-age reflects both low height-for-age and low weight-for-age and therefore reflects both cumulative and acute exposures of malnutrition. Ethiopia has a high prevalence of acute and chronic malnutrition with almost half of Ethiopian children chronically malnourished and one-in-ten children wasted. About $47 \%$ of children under-five are stunted, $11 \%$ are wasted and $38 \%$ are underweight [7]. Nearly half of under-five death is attributable to malnutrition. Malnutrition puts children at greater risk of dying from common infections and results in increased infection and delayed recovery. Poor nutrition in the first 100 days of a child's life can also lead to stunted growth, which is irreversible and associated with impaired cognitive ability and reduced school and work performance [8]. About onethird of deaths among children below five years of age were attributed to under nutrition and it can lead children to be at greater risk of death and severe illness due to common childhood infections such as pneumonia, diarrhoea, malaria, human immune deficiency virus, or AIDS and measles [9,10].

In Ethiopia, the levels of under nutrition are not decrease significantly. The EDHS [11] report showed that stunting was $58 \%$ in $2000,51 \%$ in 2005 , and $44 \%$ in 2011 . This report also showed that wasting was $12 \%$ from 2000 to 2005 and $10 \%$ in 2011 . The third predictor is underweight, which was $41 \%$ in $2000,33 \%$ in 2005, and $29 \%$ in 2011 [12]. Prevalence of malnutrition in Sebeta, Oromia, Ethiopia was identified that $46 \%$ children were malnourished and $10.9 \%$ were severely malnourished. More specifically $22.6 \%, 16.1 \%$ and $\mathrm{p} 7.4 \%$ children were stunted, underweight and wasted, respectively. Though $6.1 \%, 3 \%$ and $1.7 \%$ children were severely stunted, severely underweight and severely wasted, respectively [13]. For percent of children under age five were stunted, $9 \%$ were wasted and $25 \%$ underweight in Ethiopia [14]. Even though the government health sector developments plan with targeted supplementary food and transitioning of enhanced outreach strategy into the health extension program, health facility nutrition services. Besides, community based nutrition and micronutrient interventions and essential nutrition actions integrated infant and young feeding counselling services continues to improve the nutritional status of mothers and children through different programs but under nutrition among children is still a common problem in Ethiopia [15]. In Oromia region, prevalence of child malnutrition indicated that $26 \%$ are underweight with $7.8 \%$ severe underweight, $9.7 \%$ of the children are wasted $2.8 \%$ severe wasting and $41.4 \%$ of the children are stunted with $18 \%$ sever stunting [16]. Similar to other parts of the country Oromia region prevalence of child malnutrition is also serious public health problem. As discussed above, Bishoftu town is 
vulnerable to malnutrition and there is a common case of under-five malnutrition in OPD at Bishoftu Hospital. In Bishoftu town, because of malnutrition, many under five children became underweight, wasted and stunted because of socioeconomic, demographic, cultural problem and inadequate Breast feeding and lack of knowledge of Mother's that complementary feeding is important for children.

Despite the fact that malnutrition is one of the major public problems in Ethiopia, limited information is available on prevalence of malnutrition and associated factors in Bishoftu town. Besides, the high percentage of death malnutrition rate in the country is alarming which needs further study to describe the intervention and to assess the factors contributing to problem. Therefore, this study was aimed to assess the prevalence of under nutrition and associated factors among children of aged 6 months - 59 months in Bishoftu town, Oromia Regional State, Ethiopia, 2018/9.

\section{Conceptual Framework}

This conceptual framework adapted and modified for the prevalence and associated factors of malnutrition among 6 months - 59 months aged children in Bishoftu town. In developing countries and particularly in Sub-Saharan Africa, under-five child malnutrition is normally associated with a large number of factors to the extent that it sometimes becomes difficult to predict the risk factors (Victoria et al., 1997). Such associated factors act through a number of interrelated proximate determinants to bring about under five malnutrition that is stunting, underweight and wasting. The demographic and socio-economic factors (Child and maternal factors) such as age of child, birth order, mother's education level, marital status, mothers' age at birth, as well as maternal occupation work through proximate variables like practice of breast feeding and mother's health seeking behaviours are associated with under five malnutrition.



Figure 1: Conceptual Framework showing the prevalence of malnutrition and associated factor of UFAC. (Source: researcher modified work, 2019).

\section{DESCRIPTION OF THE STUDY AREA} AND RESEARCH METHODS

\section{Description of the study area}

The study was conducted in Bishoftu town which is geographically located in the Eastern Shewa Zone of the Oromia Region located between 80045 North latitude and 38059 East longitudes with an elevation of 1,920 meters. Bishoftu is located 47.9 kilometres southeast of Addis Ababa along its route four highway. Bishoftu town has currently estimated projected total population of 171,115 of which about 81,047 are women and 90,068 males based on the 2007 National Census Agency. People are engaged in various Socio economic activities Small and micro enterprises, large scale, government employees etc. Bishoftu town have 15 kebele, one referral Hospital, five Health canter and 45 health extension agents that they providing health service and health extension services. 


\section{Research approach and design}

Community-based cross-sectional descriptive survey study was employed to collect relevant and sufficient information within short period of time. The study design was used quantitative and qualitative research approach to assess the complexes variables of the child malnutrition prevalence and associated factors among under five children in Bishoftu town. The study period was from January 18 to February 22 2018/9.

\section{Source and study population}

The source of population was children age 6 months - 59 months pair with their mothers or caregivers lived in four kebele of study area. The study population was randomly selected households of the selected kebele dwellers.

\section{Inclusion and exclusion criteria}

Mothers or caregivers who have children age 6 months 59 months whose residents in Bishoftu town at least for six months prior to the data collection was included to participate under this study as respondent. While, manner visitors of the selected household during the data collection who have a child age 6 months - 59 months were not included under the study.

\section{Data sources}

Both primary and secondary sources of data were used to gather the information required for the study. The primary data was collected from eligible respondent's mother or caregiver of the index child and anthropometric measurement. While, secondary data were collected from available document at Health Centre, Office and Extension workers.

\section{Sample size determination}

Sample size was determined Cochran (1963:75) formula to yield the required sample for proportions were used as Cited by Israel (1992).

$$
\mathbf{n}=\frac{(\mathbf{Z \alpha} / 2)^{2} \mathbf{p}(\mathbf{1}-\mathbf{p})}{\mathbf{d}^{2}}=384
$$

$\mathrm{n}=$ is the desired sample size, $\mathrm{Z}=$ is the standard normal deviation at a confidence level set at $95 \%$ which is 1.96 , $\mathrm{p}=$ estimated proportion of an attribute that is present in the population, $\mathrm{q}=$ is the proportion of an attribute that without population, $\mathrm{d}=$ desired level of precision.

The total population (total children age 6-59 months) of the towns are 12,257; need to adjust using finite population correlation factors. Because, it was advisable to adjust the sample size to finite population correction factor applied when the sample represents a significant (e.g. over $5 \%$ ) proportion of the population as cited by Susan et al. (2015). The formula should be:

$$
n_{a}=\frac{n}{1+\frac{n-1}{N}}
$$

Where: $\mathrm{n}_{\alpha}=$ the required sample size, $\mathrm{N}=$ the total population of the children age 6-59 months in the study area, $\mathrm{n}=$ the sample size estimated based on the assumption of $\mathrm{p}=0.50$. Hence substituting the formula sample size $=373$, so with adjustment for non-response $(10 \%) \mathrm{n}=(373+37)$, the final sampling size was 410 children.

\section{Sampling techniques}

The study area was purposively selected multistage sampling technique followed by simple random sampling was used to select children from households. From 15 kebele namely kebele 01, 03, 05 and 07 kebele were select by simple random sampling method. Study participants/households/care takers were also selected kebele by proportionate allocation from each selected kebele. Study participants were selected by simple random sampling (table of random numbers) based on frame existing in health posts, from households with children 6 to 59 months in these four Kebele. Participants of the focus group discussions (FGDs) were selected to take part with the help of village elders and Health Extension Workers (HEWs). This ensured that participants who were easily accessible and those who have adequate information regarding child feeding in the study area have been 
selected. To enhance homogeneity, each FGD of participant was made up of 6 to 14 mothers with children below 2 years who will not be part of the main sample. The FGDs will be held in all the four Kebele after quantitative data had been collected.

\section{Tools and techniques of data collection}

In this study information was collected using structured questionnaire which was administered to eligible respondent's mothers/caregivers of child to obtain quantitative data. Focus group discussion was also conducted to collect qualitative data. A close supervision of enumerator during the field work and administration (FGD) from different economic status household was done through the principal investigator. In addition to investigate the nutritional status of the children anthropometric measurement on height, weight, and MUAC was taken from each sample child. Weight of the child has been measured by using weight scale and their height was measured through measuring board while MUAC was measured using WHO standard MUAC tape. The height of infants aged 6 months - 23 months (less than $85 \mathrm{~cm}$ ) calculated in recumbent position while for children aged 24 months - 59 months was measured in stand up position. Accordingly, Weight of the infants and measured to the nearest $10 \mathrm{~g}$ by standard weight scale for a child who stand alone and as well for not stand alone the mother was weighted together with a child and then without the child. The difference during data collection the researcher has checked and followed up in the field and observed how well data collectors were doing their task. At the end of the data collection check the completeness of filled questioner. At the end of every day filled data collection.

\section{Data quality assurance}

To maintain the quality of data the questionnaire was first prepared in English and later translated into Afan Oroma (the local language of the study area) and back translated into English to check for its conceptual equivalence. The data was collected by 6 data collectors who have health related background and able to communicate, reading and writing Afan Oroma and Amharic languages. The data collectors were recruited from Hospital and health center. Inanition two days training has been provided for data collectors with regards to administration of the questionnaire and anthropometric measurement. To ensure the quality of research data, data collectors were taken one-day training on the how to administer structured questionnaires and take anthropometric measurements. Measurements was taken using standard instruments of weighting scale and height board and routinely checked and adjusted to maintain its accuracy, precision and validity. For instance, every day similar weight was taken by investigator before starting weighting of child and zero reading was checked following weighing child.

\section{Study variables}

The dependent variables were wasting, underweight and stunting. While the factors assessed as independent variables were; feeding, health care seeking, hygiene and immunization, age, sex, birth order, gestational age, types of birth, place of delivery, breast-feeding status and morbidly status, head of HHs, ethnicity, religion, family size, marital status, occupation income, education, ownership of livestock and farm land. Moreover, extra food during pregnancy/lactation, number of children ever born, use of extra food during pregnancy or lactation and autonomy in decision-making on use of money were also taken as independent variables.

\section{Data analysis procedure}

The quantitative data collected through structured questionnaire was entered into Epi-Data version 3.1 and exported to STATA 13 for analysis. To convert the anthropometric data into Z-scores of the indices WHO Anthro 2011 version 3.2.2, software was used for stunting HAZ (Height for Age Z-score), underweight WAZ (Weight for Age Z-score) and wasting WHZ (Weight for Height Z-score) and exported STATA 13 for further analysis. Descriptive statistical analysis was used to 
compute frequency percentage, mean and standard deviation was used to organize distribution of child demographic, household's demographic, socioeconomic, and maternal \& child caring practice. Bivariate regression model was used first to identify the association between independent determinants and outcome variables. As well multivariate regression used to estimate the imperative determinants that influence on malnutrition of children.

\section{Ethical consideration}

The ethical clearance was obtained from board of ethical committee of Addis Ababa University College of Development Studies. The permission got from related government office for conducting the research with briefing of study purpose and benefits to the community. It was planned to get the consent earlier before starting to obtain the data from respondents or any one with children before starting the interview or taking body measurements. Those respondents who were not willing to participate in the study were not forced to be involved. The respondent also being informed that all data from them measurements were kept confidential by using coding instead of any personal identifiers and is intended only for the purpose of the study.

\section{RESULT AND DISCUSSION}

\section{Result}

The study is presented as background characteristics of respondents and children, analysis of leading factors which contribute for malnutrition, bivariate analysis and multivariate analysis results of the relationship among independent variables (predictor factors) and malnutrition. From the total planned study subjects, complete response was obtained for 410(100\%) which are presented in (Table 1 and Table 2).

\section{Demographic characteristics of children and caretakers}

The background characteristics are divided into child and maternal factors in Bishoftu districts are presented in Table 1. Two hundred seventeen $52.93 \%$ male children and one hundred ninety-threes were included. The average age of children incorporated in this study was 28.62 with a minimum age 6 months and maximum age of 59 months.

\begin{tabular}{|c|c|c|c|c|c|c|}
\hline No. & Issues & \multicolumn{2}{|r|}{ Freq. } & \multicolumn{3}{|c|}{ Percent } \\
\hline \multirow[t]{4}{*}{1} & Sex of child & & & & & \\
\hline & Male & \multicolumn{2}{|l|}{217} & \multicolumn{3}{|l|}{52.93} \\
\hline & Female & \multicolumn{2}{|l|}{193} & \multicolumn{3}{|l|}{47.07} \\
\hline & Total & \multicolumn{2}{|l|}{410} & \multicolumn{3}{|l|}{100} \\
\hline \multirow[b]{2}{*}{2} & Variable & Obs & Mean & Std. Dev. & Min & Max \\
\hline & Child age in month & 410 & 28.62 & 15.54 & 6 & 59 \\
\hline 3 & Family size & 410 & 3.87 & .97 & 3 & 6 \\
\hline 4 & Number of under 5 years & 410 & 1.32 & .55 & 1 & 3 \\
\hline 5 & Mother's age & 410 & 30.22 & 5.59 & 21 & 43 \\
\hline
\end{tabular}

Table 1: Demographic characteristics of children in Bishoftu town, Oromia, $2019(\mathrm{~N}=410)$. Source: From researcher own data, 2019.

\begin{tabular}{|c|c|c|c|c|c|c|}
\hline No. & Items & \multicolumn{2}{|c|}{ Freq. } & \multicolumn{3}{|l|}{ Percent } \\
\hline \multirow[t]{3}{*}{1} & Residence & & & & & \\
\hline & Urban & \multicolumn{2}{|l|}{45} & \multicolumn{3}{|l|}{10.98} \\
\hline & Rural & \multicolumn{2}{|l|}{365} & \multicolumn{3}{|l|}{89.02} \\
\hline \multirow[t]{7}{*}{2} & Religion & & & & & \\
\hline & 1 Orthodox Christian & \multicolumn{2}{|l|}{194} & \multicolumn{3}{|l|}{47.32} \\
\hline & 2 Muslim & \multicolumn{2}{|l|}{100} & \multicolumn{3}{|l|}{24.39} \\
\hline & Catholic & \multicolumn{2}{|l|}{9} & \multicolumn{3}{|l|}{2.20} \\
\hline & Protestant & \multicolumn{2}{|l|}{98} & \multicolumn{3}{|l|}{23.90} \\
\hline & Traditional & \multicolumn{2}{|l|}{9} & \multicolumn{3}{|l|}{2.20} \\
\hline & Total & \multicolumn{2}{|l|}{410} & \multicolumn{3}{|l|}{100.00} \\
\hline \multirow[t]{7}{*}{3} & Mother education & & & & & \\
\hline & No Education & \multicolumn{2}{|l|}{83} & \multicolumn{3}{|l|}{20.24} \\
\hline & Read and Write Only & \multicolumn{2}{|l|}{20} & \multicolumn{3}{|l|}{4.88} \\
\hline & Primary School & \multicolumn{2}{|l|}{29} & \multicolumn{3}{|l|}{7.07} \\
\hline & Secondary School & 140 & & 34.15 & & \\
\hline & College and above & 138 & & 33.66 & & \\
\hline & Total & 410 & & 100.00 & & \\
\hline 4 & Occupation & & & & & \\
\hline & Farming & 18 & & 4.49 & & \\
\hline & Agro pastoralist & 18 & & 4.49 & & \\
\hline & Employment & 244 & & 60.85 & & \\
\hline & Merchandise & 52 & & 12.97 & & \\
\hline & Labourer & 69 & & 17.21 & & \\
\hline & Total & 401 & & 100.00 & & \\
\hline 5 & Marital status & & & & & \\
\hline & Unmarried & 82 & & 20.00 & & \\
\hline & Married & 301 & & 73.41 & & \\
\hline & Divorced & 9 & & 2.20 & & \\
\hline & Widowed & 18 & & 4.39 & & \\
\hline & Total & 410 & & 100.00 & & \\
\hline 6 & Head of Household & & & & & \\
\hline & 1 Mother & 18 & & 4.39 & & \\
\hline & 2 Father & 270 & & 65.85 & & \\
\hline & 3 Both & 122 & & 29.76 & & \\
\hline & Total & 410 & & 100.00 & & \\
\hline 7 & Variable & $\mathrm{Obs}$ & Mean & Std. Dev & Min & $\operatorname{Max}$ \\
\hline & Monthly income & 410 & 3652.317 & 1717.966 & 700 & 9050 \\
\hline
\end{tabular}

Table 2: Socio-economic characteristics of respondents in Bishoftu town, Oromia, $2019(\mathrm{~N}=410)$. Source: From researcher own data, 2019.

Normal family size of households involved in the study was 3.8 with a minimum 3 and maximum 6 . The maximum number of children aged 6 months - 59 months in a household were 3 and minimum was 1 and in average 
there were 1.32 children. According to the above table the maximum described by the respondents was 43 and minimum age was 21 , the mean ages of the respondents were 30.22 .

\section{Socio- economic characteristics of respondents}

As indicated in (Table 2) below, the resident of most of respondents 365 accounted for more 89 percent under the survey were in rural area while $45(10.98 \%)$ were from urban area. In this sample, 47.32 percent of the mothers were orthodox Christian, 24.39 percent were Muslims, 23.9 percent were protestants 2.2 percent were Catholics, whereas the remaining 2.2 were worshiping traditional believes. The majority of the mothers 34.15 percent have received secondary schooling, 33.66 percent had college and above educational level 20.4 percent.

\section{Prevalence of malnutrition}

\section{Overall prevalence of stunting, underweight and wasting}

With regards of prevalence of malnutrition of children among aged 6 months - 59 months in Bishoftu town as it was indicated in Table 3 were $6.9 \%$ severely stunted, 13.8 $\%$ were stunted, $2.2 \%$ were underweight and $11.2 \%$ were wasted. Moderate level of prevalence of malnutrition children aged 6 months - 59 months were seen in male.

\begin{tabular}{|l|l|l|l|l|}
\hline Indicators & $\%<3$ SD & $\%<-2$ SD & Mean & SD \\
\hline Lengthheight for age (Stunting) & 6.9 & 13.8 & 1.22 & 2.34 \\
\hline Weight for age (Underweight) & 0 & 2.2 & 0.95 & 1.2 \\
\hline Weight for Height Length (Wasting) & 0 & 11.2 & 0.14 & 1.65 \\
\hline
\end{tabular}

Table 3: Prevalence malnutrition in Bishoftu town, Oromia, $2019(\mathrm{~N}=410)$. Source: Survey result of 2019 in Bishoftu.

\section{Prevalence of stunting}

Stunting is a failure to reach linear growth potential of height relative to chronological age. Shortness is used to tell if a child is abnormal in height for age as a result of malnutrition. The higher level of Stunting was observed in male $(27.1 \%)$ as compare with girls that was $(14 \%)$. A peak degree of stunting (42.9\%) was made known among children aged 6 months - 11 months, the level of stunting among children aged 36 months - 47 months was (30\%) and followed by children aged 48 months - 59 months were $(24.4 \%)$, the lowest magnitude of stunting was perceived in children aged 12 months - 23 months (10.02\%) (Table 4).

\begin{tabular}{|l|l|l|l|l|l|}
\hline \multicolumn{1}{|c|}{ Sex } & Total Number & $\%<-3$ SD & \%<-2SD & Mean & SD \\
\hline Male & 217 & 9 & 18.1 & 0.91 & 2.4 \\
\hline Female & 193 & 4.7 & 9.3 & 1.54 & 2.24 \\
\hline $\begin{array}{l}\text { Age group in } \\
\text { month }\end{array}$ & \multicolumn{5}{|c|}{} \\
\hline$(6-11)$ & 63 & 14.3 & 28.6 & -0.83 & 2.05 \\
\hline$(12-23)$ & 120 & 0 & 8.1 & 2.92 & 2.06 \\
\hline$(24-35)$ & 84 & 0 & 10.7 & 1.34 & 1.72 \\
\hline$(36-47)$ & 60 & 15 & 15 & 0.71 & 2.28 \\
\hline$(48-59)$ & 83 & 12.2 & 12.2 & 0.69 & 1.84 \\
\hline
\end{tabular}

Table 4: Prevalence of stunting in Bishoftu Town, Oromia, Ethiopia, $2019(\mathrm{~N}=410)$.

\section{Prevalence underweight by sex and age group weight}

for age

Table 5 was indicated that $4.1 \%$ of male children were categorized as underweighted as weighed against girls. The current status of body proportion of with their sequential age $10.8 \%$ of children grouped under the age category of 48 months - 59 months were not linear in other word underweighted.

\begin{tabular}{|l|l|l|l|l|l|}
\hline Sex & Total Number & \%<-3SD & \%<-2SD & Mean & SD \\
\hline Male & 217 & 0 & 4.1 & 0.98 & 1.42 \\
\hline Female & 193 & 0 & 0 & 0.91 & 0.91 \\
\hline Age group in month & & & & & \\
\hline$(6-11)$ & 63 & 0 & 0 & 0.78 & 1.13 \\
\hline$(12-23)$ & 120 & 0 & 0 & 2.26 & 0.5 \\
\hline$(24-35)$ & 84 & 0 & 0 & 0.52 & 0.76 \\
\hline$(36-47)$ & 60 & 0 & 0 & 0.94 & 0.44 \\
\hline$(48-60)$ & 83 & 0 & 10.8 & -0.38 & 0.82 \\
\hline
\end{tabular}

Table 5: Prevalence underweight (sex and age group weight for age) in Bishoftu town, Ethiopia, $2019(\mathrm{~N}=410)$.

\begin{tabular}{|l|l|l|l|l|l|}
\hline \multicolumn{1}{|c|}{ Sex } & Total Number & \%<-3SD & \%<-2SD & Mean & SD \\
\hline Male & 217 & 0 & 10.6 & 0.47 & 1.35 \\
\hline Female & 193 & 0 & 12 & -0.23 & 1.86 \\
\hline Age group in month & & & & & \\
\hline$(6-11)$ & 63 & 0 & 0 & 1.26 & 1.86 \\
\hline$(12-23)$ & 120 & 0 & 0 & 1 & 1.4 \\
\hline$(24-35)$ & 84 & 0 & 23.8 & -0.28 & 1.26 \\
\hline$(36-47)$ & 60 & 0 & 0 & -0.15 & 0.98 \\
\hline$(48-69)$ & 83 & 0 & 31.1 & -1.42 & 1.14 \\
\hline
\end{tabular}

Table 6: Prevalence of Wasting (Sex and Age Group Weight for Height/Length) in Bishoftu town, Ethiopia, 2019, $(\mathrm{N}=410)$.

\section{Prevalence of wasting sex and age group weight for height/length}

Table 6 is indicated that $(10.6 \%)$ of boys and (12\%) of girls were wasted in addition (31.1\%) and (23.8\%) 
occurrence of wasting (low weight-for-height) was seen in the age group of 48 months - 59 months and 24 months 35 months, respectively.

\section{Prevalence of MUAC for age Z-Score in Bishoftu}

The MUAC measurement result is an indicator of immediate acute malnutrition for children age 6 months 59 months. To vigour the results of weight for height $\mathrm{Z}$ score (wasting) MAUC for age Z-score (MUACZ) was estimated. Therefore, $2.2 \%$ of children were affected by acute malnutrition 14.6 were slightly higher than the result observed in the weight for height measurement. As it was pointed up in Table 7, that superior level $34.9 \%$ of malnutrition was observed in the age group of 48-59 moths followed by score $23.8 \%$ malnutrition among the age group of 24 months - 35 months (Table 7).

\begin{tabular}{|l|l|l|l|l|l|}
\hline MUAC for age Z-Score & $\begin{array}{l}\text { Total } \\
\text { Number }\end{array}$ & $\%<-3$ SD & $\%<-2$ SD & Mean & SD \\
\hline MUAC for age & 410 & 2.2 & 14.6 & -0.96 & 0.89 \\
\hline Age group in month & & & & & \\
\hline$(6-11)$ & 63 & 0 & 0 & -0.66 & 0.57 \\
\hline$(12-23)$ & 120 & 0 & 16.7 & -0.94 & 0.69 \\
\hline$(24-35)$ & 84 & 0 & 23.8 & -1.43 & 1 \\
\hline$(36-47)$ & 60 & 0 & 0 & -0.35 & 0.83 \\
\hline$(48-59)$ & 83 & 10.8 & 24.1 & -1.16 & 0.95 \\
\hline
\end{tabular}

Table 7: Prevalence of MUAC for age Z-Score in Bishoftu town, Ethiopia, 2019, $(\mathrm{N}=410)$.

\section{Nutritional practice of family}

The amount of expenditure spent for food consumption from monthly income which is determinant to malnutrition was also assessed in the study and as pointed up in table $4.884 .63 \%, 6.59 \%, 2.2 \%$ and $6.59 \%$ were witnessed that they were paying for household food consumption, children education, purchasing of cows and purchase of clothed, respectively. At the same table more than three fourth $84.63 \%$ of respondents indicated that they were buying their food from markets the remaining $10.98 \%, 2.2 \%$ and $2.2 \%$ or respondents identified Aid donation, shared market and other sources of supplies as sources of food in chronological order.

As indicated in Table 8 below, the highest information gained about nutrition $31.95 \%$ was from health extension workers and the second $28.78 \%$ source of information was from relatives, friends and families; whereas: $4.39 \%$ form magazine and newspaper, $12.20 \%$ form television, $10.24 \%$ from mobile telephone and $10.24 \%$ were gotten from radio. However, $2.2 \%$ of respondents indicated that they have not get information from any of the sources.

\begin{tabular}{|c|c|c|c|}
\hline No. & Items & Freq. & Percent \\
\hline \multirow[t]{6}{*}{1} & Expenditure spend & & \\
\hline & Household food consumption & 347 & 84.63 \\
\hline & Children Education & 27 & 6.59 \\
\hline & Purchasing of cow & 9 & 2.20 \\
\hline & Purchase of clothes & 27 & 6.59 \\
\hline & Total & 410 & 100.00 \\
\hline \multirow[t]{6}{*}{2} & Main Sources of Food & & \\
\hline & Market & 347 & 84.63 \\
\hline & Aid Donation & 9 & 2.20 \\
\hline & Shared production & 45 & 10.98 \\
\hline & Others & 9 & 2.20 \\
\hline & Total & 410 & 100.00 \\
\hline \multirow[t]{9}{*}{3} & Source of Information about Nutrition & & \\
\hline & Magazine and Newspaper & 18 & 4.39 \\
\hline & Television & 50 & 12.20 \\
\hline & Mobile telephone & 42 & 10.24 \\
\hline & Radio & 42 & 10.24 \\
\hline & Relative/friend/family & 118 & 28.78 \\
\hline & Health extension workers & 131 & 31.95 \\
\hline & No information & 9 & 2.20 \\
\hline & Total & 410 & 100.00 \\
\hline \multirow[t]{5}{*}{4} & Means of transportation & & \\
\hline & Vehicles & 95 & 23.17 \\
\hline & Bajaj & 243 & 59.27 \\
\hline & Don't use any transport system & 72 & 17.56 \\
\hline & Total & 410 & 100.00 \\
\hline
\end{tabular}

Table 8: Nutritional practice, means of transportation and information of family in Bishoftu town, Oromia, Ethiopia, 2019, $(\mathrm{N}=410)$.

With regards to the transportation system used by the respondents' majority of the respondents $59.27 \%$ were using Bajaj while 23.17 pointed out that they were transporting their food through vehicles and the remaining $17.56 \%$ were not using transportation.

\section{Health conditions of children}

As the result shows in Table 9 that $83.66 \%, 86.83 \%$, $86.83 \%, 70.9 \%$ and $63.41 \%$ of children were vaccinated in BGC, PCV, Polio, Measles, Penta valent and Vitamin A, respectively. Out of the total of children only $63.41 \%$ were completed their vaccination, while 38(9.27) children were not received any type of vaccination. Concerning 
health history of children $8.78 \%$ of children had diarrhoea, $7.07 \%$ respiratory disease, $4.39 \%$ measles, $11.46 \%$ fever, $20.98 \%$ cough and $6.59 \%$ vomiting.

\section{Awareness towards breast feeding}

The result Table 10 shows that the majority $86.83 \%$ mother's perceived breastfeeding as crucial for the child development, however, $13.17 \%$ of respondents were not recognize breastfeeding as an important. Sixty six point eight three $(66.83 \%)$ of the respondents were providing breast milk only for their newly born child, $19.02 \%$ were deliver formula milk and the remaining $14.15 \%$ were supplying plain water with breast milk. With regards to the length of breastfeeding $42.2 \%$ were provides breast milk for more than 6 months their children, $27.56 \%$ were feed their children breast milk for 4 months - 6 months only, $18.78 \%$ were nourish breast milk for less than 4 months and the remaining $11.46 \%$ were never feed breast milk for their children. The view of female towards the importance of breast milk is a determinant point for eradicating malnutrition, bearing this in mind mothers were asked for their perception to indicate whether feeding breast milk is harmful or not accordingly $91.22 \%$ were denied it. And the remaining $8.78 \%$ were confirming that nourishing the child with breast milk is harmful. Consequently, another question was forwarded to know whether bottle feeding is harmful or not and $68.05 \%$ were agreed and the remaining $31.95 \%$ were disagreed.

The practice of breastfeeding also was raised as an issue and $95.61 \%$ of respondents were previously had an experience of breastfeeding where as $4.39 \%$ of mothers do not have past experience of breastfeeding. In addition, $52.93 \%$ of respondents were currently implementing breastfeeding while $47.07 \%$ of respondents were not currently nourishing breast milk for their children. Of total respondents $60.10 \%$ were stop to breastfeeding in order to start additional food, $13.99 \%$ were discontinue breastfeeding by perceiving breast milk has not an adequate amount of food, others $13.88 \%$ of mothers impede breastfeeding in order to prevent themselves from tiredness, $10.36 \%$ were brought to an end of breastfeeding due to pregnancy while $4.66 \%$ were ended up breast feeding based on an insight of breast milk can able to destroy child's health.

Sixty-seven $(28.51 \%)$ mothers out of the total participants responds that they don't know how many times they gave breastfeed their children, and $61(25.31 \%)$ pointed out that they provide breastfeed more than eight times a day, $51(29.6 \%)$ were notified that they offer breastfeed 4 up to 7 times a day. Only 23(16.17\%) of mothers responds' that they offered breast feed for less than or equal to three times per twenty-four hours.

\begin{tabular}{|l|l|l|l|l|l|}
\hline \multirow{2}{*}{ No. Issues } & \multicolumn{2}{c|}{ Yes } & \multicolumn{2}{c|}{ No } \\
\cline { 3 - 6 } & & Freq. & Percent & Freq. & Percent \\
\hline 1 & Child vaccination & 372 & 90.73 & 38 & 9.27 \\
\cline { 2 - 6 } & BCG & 343 & 83.66 & 67 & 16.34 \\
\cline { 2 - 6 } & PCV & 356 & 86.83 & 54 & 13.17 \\
\cline { 2 - 6 } & Polio & 356 & 86.83 & 54 & 13.17 \\
\cline { 2 - 6 } & Measles & 291 & 70.98 & 119 & 29.02 \\
\cline { 2 - 6 } & Pentavalent & 356 & 86.83 & 54 & 13.17 \\
\cline { 2 - 6 } & Vitamin A & 260 & 63.41 & 150 & 36.59 \\
\hline 2 & Health condition & & & & \\
\cline { 2 - 6 } & Diarrhoea & 36 & 8.78 & 374 & 91.22 \\
\cline { 2 - 6 } & Respirator & 29 & 7.07 & 381 & 92.93 \\
\cline { 2 - 6 } & Measles & 18 & 4.39 & 392 & 95.61 \\
\cline { 2 - 6 } & Fever & 47 & 11.46 & 363 & 88.54 \\
\cline { 2 - 6 } & Cough & 86 & 20.98 & 324 & 79.02 \\
\cline { 2 - 6 } & Vomiting & 27 & 6.59 & 383 & 93.41 \\
\cline { 2 - 6 } & Take to health institution & 74 & 18.05 & 336 & 81.95 \\
\hline
\end{tabular}

Table 9: Health conditions of children in Bishoftu town, Oromia, Ethiopia, 2019, ( $\mathrm{N}=410)$.

Respondents were asked about the type of food provided to their children and $42.44 \%$ have gave their children breast milk, $31.22 \%$ had offer them cow's milk $16.34 \%$ have provide them fruit juice and only $10 \%$ mothers' deliver formula milk for their children.

\section{Provision of complementary foods}

The result Table 11 showed that $55.11 \%$ of mothers included in this study were starts after 6 months to deliver complementary food for their children, $24.44 \%$ were started it at 6 months while the remaining indicates that they have started before the age of 6 months.

Identifying the underlying grounds that push of delivery of early complementary food in a particular locality is important to solve the nutrition problems (Table 12). 


\begin{tabular}{|c|c|c|c|c|c|}
\hline No & \multirow{2}{*}{ Issues } & \multicolumn{2}{|c|}{ Yes } & \multicolumn{2}{|c|}{ No } \\
\hline & & \begin{tabular}{|l|} 
Freq. \\
\end{tabular} & Percent & Freq. & Percent \\
\hline \multirow[t]{2}{*}{1} & Mothers' awareness towards breast feeding. & & & & \\
\hline & Breast feeding is important & 356 & 86.83 & 54 & 13.17 \\
\hline \multirow[t]{4}{*}{2} & Important for newly borm & \multicolumn{2}{|c|}{ Freq. } & \multicolumn{2}{|c|}{ Percent } \\
\hline & Brestmilk only & \multicolumn{2}{|l|}{274} & \multicolumn{2}{|c|}{66.83} \\
\hline & Breast milk with plain water & \multirow{2}{*}{\multicolumn{2}{|c|}{$\frac{58}{78}$}} & \multirow{2}{*}{\multicolumn{2}{|c|}{$\frac{14.15}{19.02}$}} \\
\hline & \begin{tabular}{|l} 
Formula milk \\
\end{tabular} & & & & \\
\hline \multirow[t]{8}{*}{3} & Duration of EBF & & \\
\hline & NoEBF & \multicolumn{2}{|l|}{47} & \multicolumn{2}{|l|}{11.46} \\
\hline & $<4$ months & \multirow{2}{*}{\multicolumn{2}{|c|}{$\frac{77}{173}$}} & \multicolumn{2}{|l|}{18.78} \\
\hline & $>6$ months - & & & 42.20 & \\
\hline & $4-6$ months & \multicolumn{2}{|l|}{113} & \multicolumn{2}{|l|}{27.56} \\
\hline & Total & \multicolumn{2}{|c|}{410} & \multirow{2}{*}{\multicolumn{2}{|c|}{100.00}} \\
\hline & \multirow[t]{2}{*}{ Variables } & \multicolumn{2}{|l|}{ Yes } & & \\
\hline & & Freq. & \begin{tabular}{|l|} 
Percent \\
\end{tabular} & Freq. & Percent \\
\hline 4 & \begin{tabular}{|l|} 
Breastfeed is harm \\
\end{tabular} & 36 & 8.78 & 374 & 91.22 \\
\hline 5 & Bottle feed is harm & 131 & 31.95 & 279 & 68.05 \\
\hline 6 & Previously practised breast feeding & 392 & 95.61 & 18 & 4.39 \\
\hline$=$ & Currently breast feading & 217 & 52.93 & 193 & 47.07 \\
\hline \multirow[t]{7}{*}{8} & \begin{tabular}{|l|l|} 
Main reas on for not giving Breast millk \\
\end{tabular} & & req. & & \\
\hline & Breast milk is not enough & 27 & & 13.99 & \\
\hline & Child starts to take additional solid & 116 & & 60.10 & \\
\hline & Breast milk make child sick & 9 & & 4.66 & \\
\hline & Mothers tired of breastfeeding & 21 & & 10.88 & \\
\hline & Mother's pregnancy & 20 & & 10.36 & \\
\hline & Total & 193 & & 100.00 & \\
\hline 9 & \begin{tabular}{|l} 
How many time did you feed in last 24 hours \\
\end{tabular} & & & & \\
\hline & $<3$ times & 38 & & 16.17 & \\
\hline & $4-7$ times & 51 & & 29.36 & \\
\hline & $\geq 8$ times & 61 & & 25.96 & \\
\hline & Idon'tKnow & 67 & & 28.51 & \\
\hline & Total & 217 & & 100.00 & \\
\hline 10 & $\begin{array}{l}\text { Type food feed last } 24 \text { hour including day } \\
\text { and night }\end{array}$ & . & & & \\
\hline & \begin{tabular}{|l} 
Caw's Milk \\
\end{tabular} & 128 & & 31.22 & \\
\hline & Formula milk & 41 & & 10.00 & \\
\hline & \begin{tabular}{|l} 
Breastmilk \\
\end{tabular} & 174 & & 42.44 & \\
\hline & Fruitjuice & 67 & & 16.34 & \\
\hline & Total & 410 & & 100.00 & \\
\hline
\end{tabular}

Table 10: Breast feeding in Bishoftu town, Oromia, Ethiopia, 2019, $(\mathrm{N}=410)$.

\begin{tabular}{|c|c|c|c|c|c|}
\hline $\mathrm{N}_{0}$ & Variables & \multicolumn{2}{|c|}{ Yes } & \multicolumn{2}{|c|}{$\mathrm{N}_{0}$} \\
\hline \multirow[t]{2}{*}{1} & & Freq. & Percent & Freq. & Percent \\
\hline & $\begin{array}{l}\text { Do you deliver complementary food for your } \\
\text { children }\end{array}$ & 410 & 100 & - & - \\
\hline \multirow[t]{5}{*}{2} & When start complementary feeding & \multicolumn{2}{|l|}{ Freq. } & \multicolumn{2}{|c|}{ Percent } \\
\hline & $>6$ months & \multicolumn{2}{|l|}{221} & \multicolumn{2}{|l|}{55.11} \\
\hline & At 6 months & \multicolumn{2}{|l|}{98} & \multicolumn{2}{|l|}{24.44} \\
\hline & $<6$ months & \multicolumn{2}{|l|}{82} & \multicolumn{2}{|l|}{20.45} \\
\hline & Total & \multicolumn{2}{|l|}{401} & \multicolumn{2}{|c|}{100.00} \\
\hline \multirow[t]{12}{*}{3} & Reason for early complementary feeding & & & & \\
\hline & Inadequacy of breast milk & \multicolumn{2}{|l|}{197} & \multicolumn{2}{|l|}{48.05} \\
\hline & Being deficient in time & \multicolumn{2}{|l|}{21} & \multicolumn{2}{|l|}{5.12} \\
\hline & To motivate child to start food & \multicolumn{2}{|l|}{9} & \multicolumn{2}{|l|}{2.20} \\
\hline & Child reaching for food & \multicolumn{2}{|l|}{40} & \multicolumn{2}{|l|}{9.76} \\
\hline & Child becomes active & \multicolumn{2}{|l|}{27} & \multicolumn{2}{|l|}{6.59} \\
\hline & Child always crying & \multicolumn{2}{|l|}{9} & \multicolumn{2}{|l|}{2.20} \\
\hline & Good for child growth & \multicolumn{2}{|l|}{51} & \multicolumn{2}{|l|}{12.44} \\
\hline & Protects child from disease & \multicolumn{2}{|l|}{29} & \multicolumn{2}{|l|}{7.07} \\
\hline & No reason at all & \multicolumn{2}{|l|}{9} & \multicolumn{2}{|l|}{2.20} \\
\hline & Tradition thinking & \multicolumn{2}{|l|}{18} & \multicolumn{2}{|c|}{4.39} \\
\hline & Total & \multicolumn{2}{|l|}{410} & 100.00 & \\
\hline
\end{tabular}

Table 11: Provision of complementary foods in

Bishoftu town, Oromia, Ethiopia, 2019, ( $\mathrm{N}=410)$.
$48.05 \%$ of respondents indicated that inadequacy of breast milk the main reason, $12.44 \%$ of mothers pointed out that it is because they thrust that early provision is good for the child, $9.76 \%, 7.07 \%, 6.59 \%, 4.39 \%, 5.12 \%, 2.2 \%, 2.2 \%$, were indicates that as it is because of the fact that child reaching, to protect children from disease, to make their children active, traditional thinking, inadequacy time to feed their children, to keep out of their children from crying and without any reason, respectively.

\begin{tabular}{|c|c|c|c|c|c|}
\hline \multirow[t]{2}{*}{ No. } & \multirow[t]{2}{*}{ Issues } & \multicolumn{2}{|c|}{ Yes } & \multicolumn{2}{|c|}{ No } \\
\hline & & Freq. & percent & Freq. & Percent \\
\hline \multirow[t]{8}{*}{1} & Child take any liquid & 229 & 55.85 & \begin{tabular}{|l|l|}
181 \\
\end{tabular} & 44.15 \\
\hline & If no Why do not feed the diversified diet & \multicolumn{2}{|l|}{ Freq. } & \multicolumn{2}{|c|}{ Percent } \\
\hline & It has no advantage. & \multicolumn{2}{|l|}{39} & \multicolumn{2}{|l|}{21.96} \\
\hline & The child may not like it. & \multicolumn{2}{|l|}{43} & \multicolumn{2}{|l|}{23.83} \\
\hline & It is Culturally forbidden. & \multicolumn{2}{|l|}{29} & \multicolumn{2}{|l|}{13.55} \\
\hline & $\begin{array}{l}\text { It may cause discomfort and illness for a } \\
\text { child }\end{array}$ & \multicolumn{2}{|l|}{9} & \multicolumn{2}{|l|}{4.21} \\
\hline & $\begin{array}{l}\text { High market price of vitamin A rich food } \\
\text { source's }\end{array}$ & \multicolumn{2}{|l|}{61} & \multicolumn{2}{|l|}{36.45} \\
\hline & Total & \multicolumn{2}{|l|}{181} & \multicolumn{2}{|c|}{100.00} \\
\hline \multirow[t]{7}{*}{2} & $\begin{array}{l}\text { Frequency of breast and complementary } \\
\text { feading }\end{array}$ & & & & \\
\hline & Immediately/within lhour & \multicolumn{2}{|l|}{202} & \multicolumn{2}{|l|}{51.53} \\
\hline & After first hour & \multicolumn{2}{|l|}{51} & \multicolumn{2}{|l|}{\begin{tabular}{|l|l}
13.01 \\
13.01
\end{tabular}} \\
\hline & After more than one day & \multirow{2}{*}{\multicolumn{2}{|c|}{$\frac{9}{72}$}} & \multicolumn{2}{|l|}{2.30} \\
\hline & Don't remember/ don't know & & & 18.36 & \\
\hline & After $7-12$ hour & \multicolumn{2}{|l|}{58} & 14.80 & \\
\hline & Total & 392 & & 100.00 & \\
\hline 3 & $\begin{array}{l}\text { How often does the bresstfeed given for a } \\
\text { child }\end{array}$ & & & & \\
\hline & $14-6$ time $\mathrm{g}$ dav & 131 & & 31.60 & \\
\hline & $2>8$ time a day & 279 & & 68.04 & \\
\hline & Total & 410 & & 100.00 & \\
\hline 4 & & & Yes & & No \\
\hline & & Freq. & percent & Freq. & Percent \\
\hline & Did exclusively breast fead & & 15.37 & 347 & 84.63 \\
\hline & If yes For How long? & & req. & & rcent \\
\hline & 1No EBF & 9 & & 7.14 & \\
\hline & $2<4$ months & 9 & & 7.14 & \\
\hline & $34-6$ months & 18 & & 14.29 & \\
\hline & $4>6$ months & 27 & & 71.43 & \\
\hline & Total & 63 & & 100.0 & \\
\hline 5 & & & Yes & & No \\
\hline & & Freq. & Percent & Freq. & Percent \\
\hline & Give colostrums & 307 & 74.88 & 103 & 25.12 \\
\hline & Reas on for not giving colostrum & Freq. & & Percer & \\
\hline & I had not white milk & 26 & & 25.24 & \\
\hline & Everybody say it is shouldn't be given & 21 & & 20.39 & \\
\hline & First milk is dirty like bus & 56 & & 54.37 & \\
\hline & Total & 103 & & 100.0 & \\
\hline
\end{tabular}

Table 12: Complementary food in Bishoftu town, Oromia, Ethiopia, 2019, $(N=410)$. Source: Survey result of (2019) in Bishoftu.

\section{Preparation and provision complementary foods}

The result Table 13 revealed that, a very high proportion of the mothers $74.39 \%$ initiated feeding of newborns with pre-lacteal feeds primarily breast milk, $14.15 \%$ provides their preliminarily their child formula milk, $9.27 \%$ uses water with breast milk as a first nutrient for their children $2.2 \%$ mothers provides sugar with water solution. Mostly used type of complementary food indicated by majority 
$33.16 \%$ was porridge followed by $30.87 \%, 20.66 \%$ and $15.31 \%$ were Injera, cow's milk and bread respectively.

\begin{tabular}{|c|c|c|c|c|c|}
\hline No. & Issues & \multicolumn{2}{|c|}{ Frequency } & \multicolumn{2}{|c|}{ Percent } \\
\hline \multirow[t]{6}{*}{1} & First nutrient & & & & \\
\hline & Water with breast milk & \multicolumn{2}{|l|}{38} & \multicolumn{2}{|l|}{9.27} \\
\hline & Breast milk & \multicolumn{2}{|l|}{305} & \multicolumn{2}{|l|}{74.39} \\
\hline & Formula milk & \multicolumn{2}{|l|}{58} & \multicolumn{2}{|l|}{14.15} \\
\hline & Sugar with water & \multicolumn{2}{|l|}{9} & \multicolumn{2}{|l|}{2.20} \\
\hline & Total & \multicolumn{2}{|l|}{410} & \multicolumn{2}{|c|}{100.00} \\
\hline \multirow[t]{6}{*}{2} & Complementary food type & & & & \\
\hline & Injera & \multicolumn{2}{|l|}{121} & \multicolumn{2}{|l|}{30.87} \\
\hline & Bread & \multicolumn{2}{|l|}{60} & \multicolumn{2}{|l|}{15.31} \\
\hline & Porridge & \multicolumn{2}{|l|}{130} & \multicolumn{2}{|l|}{33.16} \\
\hline & Cowmilk & \multicolumn{2}{|l|}{81} & \multicolumn{2}{|l|}{20.66} \\
\hline & \begin{tabular}{|l|} 
Total \\
\end{tabular} & \multicolumn{2}{|l|}{392} & \multicolumn{2}{|c|}{100.00} \\
\hline \multirow[t]{3}{*}{3} & & \multicolumn{2}{|r|}{ Yes } & \multicolumn{2}{|l|}{ No } \\
\hline & & Freg. & Percent & \begin{tabular}{|l} 
Freg. \\
\end{tabular} & Percent \\
\hline & Food prepared from different crops & 283 & 69.02 & 127 & 30.98 \\
\hline \multirow[t]{9}{*}{4} & & \multicolumn{2}{|l|}{ Freq. } & Percer & \\
\hline & Kind complementary foodprepared & & & & \\
\hline & Cereal/grain only & 59 & & 15.05 & \\
\hline & Cerealmix with pulse & 134 & & 34.18 & \\
\hline & Pulse only (beans and peas) & 60 & & 15.31 & \\
\hline & Fruits and vegetables & 110 & & 28.06 & \\
\hline & Milk and milk products & 11 & & 2.81 & \\
\hline & \begin{tabular}{|l|} 
Eggs \\
\end{tabular} & 18 & & 4.59 & \\
\hline & Total & 392 & & 100.0 & \\
\hline 5 & & & Yes & & No \\
\hline & Did you feed the child anything from a & Freg. & Percent & Freq. & Percent \\
\hline & & 215 & 52.44 & 195 & 47.56 \\
\hline & Material to use to feed your child? & Freg. & & Perce & \\
\hline & \begin{tabular}{|l|} 
1Spoon \\
\end{tabular} & 27 & & 6.59 & \\
\hline & 2 Cup & 76 & & 18.54 & \\
\hline & 3Hand & 166 & & 40.49 & \\
\hline & \begin{tabular}{|l} 
4Bottle \\
\end{tabular} & 141 & & 34.39 & \\
\hline & Total & 410 & & 100.0 & \\
\hline
\end{tabular}

Table 13: Preparation and provision complementary foods in Bishoftu town, Oromia, Ethiopia, 2019, $(\mathrm{N}=410)$.

Delivery of the type of food prepared from different types of crops was carried out by $283(69.02 \%)$ of mothers among the mothers $34.18 \%$ and $28.08 \%$ children were found in using Cereal mix with pulse, fruits and vegetables. Whereas a smallest proportion $2.81 \%$ and $4.59 \%$ of mothers were not using egg, milk and products of milk as a complimentary food for their children. As shown in the table below the number of under-five children who received feeding from a bottle with a nipple yesterday or last night was $215(52.44 \%$ ) and out of these $40.49 \%, 34.39 \%, 18.54 \%$ and $6.59 \%$ were used hands, bottle, cup and spoon, respectively. Fifty six point six one percent $(56.61 \%)$ of mothers deliver milk to their children and among these $54.36 \%$ mothers feed their children more than three times a day, $26.68 \%$ of mothers, offers milk three times per day and18.95 nourish their children with milk less than three times.

\section{Availability and preparation of cow's milk}

The result Table 14 showed that cow's milk was not available in households of $174(43.39 \%)$ while $227(56.61$ $\%$ ) of households have received cow's milk, among these $107(47.14 \%)$ of mothers feed cow's milk at least three times a day. While $76(33.48 \%$ ) were feed cow's milk to their children less than three times per a day and the remaining 44(19.38\%) gave their children cow's milk more than three times a day. With regards to preparation of cow's milk food 137(31.3\%) of study subject had prepared in soaking, germination and cooking, $57(25.11 \%)$ were prepared in soaking alone, 21(9.25\%) were prepared soaking and germination the remaining $12(5.28 \%)$ were prepared in mixed with other foods.

\begin{tabular}{|c|c|c|c|c|c|}
\hline \multirow[t]{3}{*}{ No. } & \multirow[t]{3}{*}{ Variables } & \multirow{2}{*}{\multicolumn{2}{|c|}{$\begin{array}{c}\text { Freq. } \\
\text { Yes }\end{array}$}} & \multirow{2}{*}{\multicolumn{2}{|c|}{$\begin{array}{c}\text { Percent } \\
\text { No }\end{array}$}} \\
\hline & & & & & \\
\hline & & Freq. & Percent & Freq. & Percent \\
\hline \multirow[t]{6}{*}{1} & Is milk available & 227 & 56.61 & 174 & 43.39 \\
\hline & Cow'smilk feed daily & \multicolumn{2}{|r|}{ Freq. } & \multicolumn{2}{|c|}{ Percent } \\
\hline & $>3$ times & \multicolumn{2}{|l|}{44} & \multicolumn{2}{|l|}{19.38} \\
\hline & $<3$ times & \multicolumn{2}{|l|}{76} & \multicolumn{2}{|l|}{33.48} \\
\hline & 3 times & \multicolumn{2}{|l|}{107} & \multicolumn{2}{|l|}{47.14} \\
\hline & Total & \multicolumn{2}{|l|}{227} & \multicolumn{2}{|l|}{100.00} \\
\hline \multirow[t]{6}{*}{2} & Preparation & & & & \\
\hline & Soaking alone & \multicolumn{2}{|l|}{\begin{tabular}{|l}
57 \\
\end{tabular}} & \multicolumn{2}{|l|}{25.11} \\
\hline & Soaking and germination & \multicolumn{2}{|l|}{21} & \multicolumn{2}{|l|}{9.25} \\
\hline & Soaking, germination and cooking & \multicolumn{2}{|l|}{137} & \multicolumn{2}{|l|}{60.35} \\
\hline & Mixing with other foods & \multicolumn{2}{|l|}{12} & \multicolumn{2}{|l|}{5.28} \\
\hline & Total & \multicolumn{2}{|l|}{227} & \multicolumn{2}{|l|}{100.00} \\
\hline \multirow[t]{5}{*}{3} & In what form & & & & \\
\hline & Solid & \multicolumn{2}{|l|}{32} & \multicolumn{2}{|l|}{14.09} \\
\hline & Semi-solid & \multicolumn{2}{|l|}{69} & \multicolumn{2}{|l|}{30.39} \\
\hline & Soft foods & 126 & & 55.51 & \\
\hline & Total & 227 & & 100.00 & \\
\hline 4 & $\begin{array}{l}\text { Number of feed meat /bread/milk/fruit for } \\
\text { your child (diversity food) }\end{array}$ & & & & \\
\hline & Two or three times a week & 141 & & 34.39 & \\
\hline & More than once a day & 11 & & 2.68 & \\
\hline & Once a month & 27 & & 6.59 & \\
\hline & Once a week & 135 & & 32.93 & \\
\hline & Never & 96 & & 23.41 & \\
\hline & Total & 410 & & 100.00 & \\
\hline & & Yes & & No & \\
\hline 5 & Contact health extencion worter & Freq. & Percent & Freq. & Percent \\
\hline & Contact health extension worker & 329 & 80.24 & 81 & 19.76 \\
\hline
\end{tabular}

Table 14: Availability and Preparation of Cow's Milk in Bishoftu town, Oromia, Ethiopia, 2019, ( $\mathrm{N}=410)$.

From the total study participants, $126(55.51 \%)$ prepared cow's milk food in a form of soft food, 69(30.39\%) prepared cow's milk food in a type of semi-solid the remaining $32(14.09 \%)$ of the respondents have been prepared cow's milk food in the form of solid. The majority, 1419(34.39\%) of the study participant did feed meat/bread/milk/fruit diversified food for their children 
two up to three times a week, $135(32.93 \%)$ children were eating diversified food once a week, 96(23.41\%) were never used dietary diversity at all, 27(6.59\%) were providing dietary diversity for their children and $11(2.68 \%)$ of mothers did provided their children feed meat/bread/milk/fruit diversified food.

\section{Bivariate logistic regression analysis}

The bivariate analysis (crude analysis) was conducted to find out the independent effect of each explanatory variable on the binary outcome variables. It helps to identify potential variables for the multivariate analysis. The variables associated at $10 \%$ level of significance were taken into account in order to not exclude potential determinants from the analysis at early stage.

\section{Bivariate analysis result wasting}

To determine the association between prevalence of wasting malnutrition and explanatory variables, bivariate analysis was performed using logistic regression.

\begin{tabular}{|c|c|c|c|}
\hline Independent Variables & Coefficient & $95 \% \mathrm{CI}$ & \\
\hline Residence place & & & \\
\hline Rural $^{r c}$ & & & \\
\hline Urban & $-14.60(605.00)$ & -1200.37 & 1171.16 \\
\hline Family size & $0.32 *(0.19)$ & -0.04 & 0.69 \\
\hline Level of Mother education & & & \\
\hline Nofomal education ${ }^{r c}$ & & & \\
\hline Read and write only & $15.13(1240.09)$ & -2415.40 & 2445.67 \\
\hline Primary & $15.13(1029.84)$ & -2003.31 & 2033.58 \\
\hline Secondary & $-0.43(0.42)$ & -1.26 & 0.40 \\
\hline College and above & $0.24(0.46)$ & -.67 & 1.16 \\
\hline Birth interval & $0.65^{n+1}(0.17)$ & 0.32 & 0.99 \\
\hline Child age & $-0.08^{\cdots+1}(0.01)$ & -0.10 & -0.05 \\
\hline No. children under-five & $0.50(0.35)$ & -0.19 & 1.18 \\
\hline Vitamin A supplements & & & \\
\hline$Y_{e s}^{r c}$ & & & \\
\hline No & $0.86^{*}(0.39)$ & 0.09 & 1.62 \\
\hline $\begin{array}{l}\text { Frequency of breast feed in the } \\
\text { last } 24 \text { hour }\end{array}$ & $-0.94^{n+4}(0.29)$ & -1.51 & -0.36 \\
\hline Providing enough cow's milk & & & \\
\hline$Y_{e s}^{r c}$ & & & \\
\hline No & $-1.17^{n+n}(0.39)$ & -1.93 & -0.40 \\
\hline
\end{tabular}

Table 15: Bivariate Analysis Result Wasting in Bishoftu town, Oromia, Ethiopia, 2019, $(\mathrm{N}=410)$. Note: $* * *$ significant at $1 \%$, **significant at $5 \% *$ significant at $10 \%$, unmarked not significant; RC: Reference Category; the number in the bracket indicates Standard error; CI: Confidence Interval.

As indicated in the Table 15 family size, birth interval, child's age, supply of vitamin A, frequency of breast feeding and provision of cow's milk were identified as significant predictors for wasting in the bivariate analysis. Maternal educational levels, number of under five years' children with in household were not statistically significant predictors wasting.

\section{Bivariate analysis result underweight}

According to bivariate statistical analysis in the Table 16 for underweight age of child, number of children under five years with in a household, maternal age, total number of children, birth interval, children's age and the frequency of visit the household by health extension workers were found to be statistically significant indicators. However, variables such as, birth order and the previous practice breastfeeding were not significantly associated with underweight.

\begin{tabular}{|l|l|lc|}
\hline Independent Variables & Coefficient & $95 \%$ CI & \\
\hline No children under-five & $-1.47^{* * *}(0.45)$ & -2.36 & -0.59 \\
\hline Mother age & $-0.17^{* * *}(0.61)$ & -0.29 & -0.06 \\
\hline Total number of children & $-1.31^{* * *}(0.40)$ & -2.09 & -0.54 \\
\hline Birth interval & $-0.42^{*}(0.26)$ & -0.92 & 0.08 \\
\hline Birth order & $-0.34(0.35)$ & -1.02 & 0.34 \\
\hline Child age & $-0.12^{* * *}(0.04)$ & -0.20 & -0.05 \\
\hline Ever practiced breast feeding & & & \\
\hline Yes & & & \\
\hline No & & -874.41 & 897.14 \\
\hline $\begin{array}{l}\text { Number of visit by health extension } \\
\text { worker }\end{array}$ & $-1.41^{* * *}(0.47)$ & -2.33 & -0.50 \\
\hline
\end{tabular}

Table 16: Bivariate statistical analysis for underweight age of child. Note: ***significant at $1 \%$, **significant at $5 \%$

*significant at $10 \%$, unmarked not significant; RC:

Reference Category; the number in the bracket indicates standard error; CI: Confidence Interval.

\section{Bivariate analysis result stunting}

Table 17 showed bivariate logistic regression analysis was conducted to identify the independent significant variables that affect the prevalence of stunting family size, residential area, parental marital status was associated with prevalence of stunting on children based on the survey result stunting is highly prevalence in urban than in rural residential areas. The other factors which were significantly associated with prevalence of malnutrition stunting were educational status of mothers, family size, residence place, marital status, household monthly income, and children's birth order, children's sex, birth 
interval, provision of vaccination, current condition of breastfeeding and exclusive breastfeeding practice of mothers. Whereas, prevalence of stunting was of high magnitude in female as compared with males at the same time, it is more prevalence among children whose mothers are not offer breastfeeding.

\begin{tabular}{|c|c|c|}
\hline Independent Variables & Coefficient & $95 \% \mathrm{CI}$ \\
\hline Family size & $0.43^{* \cdots}(0.16)$ & 0.11 \\
\hline \multicolumn{3}{|l|}{ Residence place } \\
\hline \multicolumn{3}{|l|}{ Rural ${ }^{\text {ne }}$} \\
\hline Urban & $1.56^{* \cdots}(0.34)$ & 0.88 \\
\hline \multicolumn{3}{|l|}{ Mothers marital status } \\
\hline \multicolumn{3}{|l|}{ Currently married ${ }^{r e}$} \\
\hline Living together & $.72 *(0.32)$ & 0.10 \\
\hline Divorced/separated & $-18.51(1848.61)$ & $\begin{array}{ll}-3641.73 & 3604.71 \\
\end{array}$ \\
\hline Windowed & $15.97(1307.17)$ & $\begin{array}{ll}-2546.03 & 2577.98 \\
\end{array}$ \\
\hline \multicolumn{3}{|l|}{ Level of Mother education } \\
\hline \multicolumn{3}{|l|}{ Nofomal education ${ }^{n}$} \\
\hline Read and write only & $16.85(1165.23)$ & $\begin{array}{|ll|}-2266.97 & 2300.67 \\
\end{array}$ \\
\hline Primary & $16.85(967.68)$ & $-1879.76 \quad 1913.46$ \\
\hline Secondary & $1.65^{* m}(0.34)$ & 2.30 \\
\hline College and above & $2.40^{\circ-1}(0.41)$ & 3.20 \\
\hline Household Monthly income & $0.0004^{\cdots \cdots}(0.00009)$ & 0.0002 \\
\hline Birth order & $0.97^{* \cdots}(0.24)$ & 1.44 \\
\hline \multicolumn{3}{|l|}{ Sex of child } \\
\hline \multicolumn{3}{|l|}{ Malene } \\
\hline Female & $0.93^{* \cdots}(0.30)$ & 0.35 \\
\hline Birth interval & $0.38^{* \cdots}(0.12)$ & 0.15 \\
\hline \multicolumn{3}{|l|}{ Vaccination } \\
\hline \multicolumn{3}{|l|}{ Yes $^{r e}$} \\
\hline No & $-1.90^{m+}(0.36)$ & -2.59 \\
\hline \multicolumn{3}{|l|}{ Currentily breast feeding } \\
\hline \multicolumn{3}{|l|}{ Yes $^{r e}$} \\
\hline No & $-0.48^{*}(0.28)$ & -1.02 \\
\hline \multicolumn{3}{|l|}{ Exclusive breast feeding } \\
\hline \multicolumn{3}{|l|}{ Yes $^{\text {re }}$} \\
\hline No & $1.87^{* \cdots}(0.31)$ & 1.26 \\
\hline
\end{tabular}

Table 17: Bivariate Analysis Result Stunting in Bishoftu town, Oromia, Ethiopia, 2019, $(\mathrm{N}=410)$. Note: $* * *$ significant at $1 \%, * *$ significant at $5 \% *$ significant at $10 \%$, unmarked not significant; RC: Reference Category; the number in the bracket indicates Standard error; CI:

Confidence Interval.

\section{Multivariate logistic regression analysis}

Multivariate logistic regression analysis was conducted to identify the independent predictor variables that affect child malnutrition. All explanatory variables up to $10 \%$ level of significance in the bivariate analysis were analysed in the multivariate model to find out the imperative determinants of child malnutrition. The table below shows the estimated coefficients of explanatory variables along with the $95 \%$ confidence interval.

\section{DISCUSSION}

\section{Multivariate analysis}

In multivariable analysis displayed in (Table 18 - Table 20) above table the multivariate analysis was identified Family size, Birth interval, Child age and Frequency of breast feed as significant determinants for wasting. While for stunting, family size, level of mother's education, birth order, currently breast feeding, exclusive breast feeding and monthly income were found as independent and statistically significant determinants. Additionally, age of child and household who hadn't got advice and not visited by health extension workers was found statistically significant determinants of underweight.

\begin{tabular}{|c|c|c|c|}
\hline Independent Variables & Coefficient & $95 \% \mathrm{C}$ & \\
\hline Family size & $-2.73^{* *}(1.16)$ & -5.01 & -0.45 \\
\hline Birth interval & $4.46^{* *}(1.97)$ & 0.59 & 8.32 \\
\hline Child age & $-0.56^{* *}(0.23)$ & -1.02 & -0.11 \\
\hline Vitamin A supplements & & & \\
\hline Yes $^{r c}$ & & & \\
\hline No & $-3.82(3.70)$ & -11.08 & 3.44 \\
\hline $\begin{array}{l}\text { Frequency of breast feed in the last } \\
24 \text { hour }\end{array}$ & $2.47^{*}(1.40)$ & -0.29 & 5.22 \\
\hline Providing enough cow's milk & & & \\
\hline Yes $^{r c}$ & & & \\
\hline No & $-0.56(3.42)$ & -7.28 & 6.15 \\
\hline
\end{tabular}

Table 18: Multivariate Analysis Result Wasting in Bishoftu town, Oromia, Ethiopia, 2019, ( $\mathrm{N}=410)$. Note: $* * *$ significant at $1 \%, * *$ significant at $5 \% *$, significant at $10 \%$, unmarked not significant; $R C$ : Reference Category; the number in the bracket indicates Standard error; CI: Confidence Interval.

\begin{tabular}{|l|l|ll|}
\hline Independent Variables & Coefficient & \multicolumn{2}{l|}{ 95\%CI } \\
\hline No of children under five & $-1.33(0.35)$ & -8.3 & 0.56 \\
\hline Mothers age & $-006(0.042)$ & -0.09 & 0.08 \\
\hline Total number of children & $0.47(0.33)$ & -1.11 & 0.17 \\
\hline Birth interval & $0.10(0.21)$ & -0.31 & 0.52 \\
\hline Birth order & $-0.34(0.35)$ & -1.02 & 0.34 \\
\hline Children age & $-0.2 *(0.01)$ & -0.05 & -0.005 \\
\hline Number of visit by extension workers & $-0.58^{* *}$ - $(0.47)$ & -1.11 & -0.05 \\
\hline
\end{tabular}

Table 19: Multivariate Analysis. Note: $* * *$ significant at $1 \%$, **significant at $5 \% *$ significant at $10 \%$, unmarked not significant; RC: Reference Category; the number in the bracket indicates Standard error; CI: Confidence Interval. 


\begin{tabular}{|c|c|c|c|}
\hline Independent Variables & Coefficient & $95 \%$ CI & \\
\hline Family size & $2.30^{* * *}(0.45)$ & 1.41 & 3.19 \\
\hline Level of Mother education & & & \\
\hline Nofomal education ${ }^{r c}$ & & & \\
\hline Read and write only & $22.00(1992.48)$ & -3883.20 & 3927.17 \\
\hline Primary & $16.08(1322.03)$ & -2575.05 & 2607.20 \\
\hline Secondary & $5.80^{* * *}(0.99)$ & 3.86 & 7.74 \\
\hline College and above & $5.08^{* * *}(1.22)$ & 2.69 & 7.48 \\
\hline Household Monthly income & $0.00037^{* *}(0.00017)$ & 0.00003 & 0.0007 \\
\hline Birth interval & $2.26^{* *}(1.10)$ & 0.11 & 4.41 \\
\hline Sex of child & & & \\
\hline Male $^{r C}$ & & & \\
\hline Female & $0.87(0.71)$ & -0.53 & 2.27 \\
\hline Vaccination & & & \\
\hline Yes $^{r c}$ & & & \\
\hline No & $-2.70(2.31)$ & -7.24 & 1.83 \\
\hline Currently breast feeding & & & \\
\hline$Y_{e s}{ }^{r c}$ & & & \\
\hline No & $-3.15^{* * *}(0.60)$ & -4.34 & -1.97 \\
\hline Exclusive breast feeding & & & \\
\hline$Y_{e s}{ }^{r c}$ & & & \\
\hline No & $2.80^{* * *}(0.61)$ & 1.61 & 4.00 \\
\hline
\end{tabular}

Table 20: Multivariate analysis result stunting in Bishoftu town, Oromia, Ethiopia, 2019, ( $\mathrm{N}=410)$.

\section{Multivariate analysis result wasting}

\section{Family size}

The study findings show that the higher family numbers in the household, the greater the chance of being wasted. However, the result is significant only at 5\% significance level. This might be the care and treatment decrease as the family number increases in the household. This finding is consistent with previous studies of which found rather than household family size number was critical and significant determinant in aggravating wasting.

\section{Birth interval}

The birth interval of child is found to be a statistically significant determinant of wasting. The positive coefficient indicates relationship that's as birth interval of child increase the child has high probability of being wasted at 5\% significance level. This result is in harmony with finding of which found birth interval was the most important positive determinants of children nutritional status in Ethiopia.

\section{Child age}

Unexpectedly, this result revealed that age of child had a negative coefficient and significant at $5 \%$. This implies that as age of the child increases the child has less risk of being wasted. This result is similarity with previous studies of $[17,18]$ which revealed that the risk of being wasting to be decrease as the age of a child increase. It might be because of wasting is a cumulative effect of short term food deficient, care and exposure to acute diseases.

\section{Frequency of breast feeding}

Wasting is also influenced by frequency of breast feeding with a statistically $10 \%$ significant positive coefficient indicating children from a less frequently breast fed has higher likelihood of being wasted compared to those high frequency of breast feeding. This finding is similar to previous studies of $[19,20]$ showed that less frequently of breast feeding children was the significantly determinant of wasting.

\section{Multivariate analysis result underweight}

\section{Age of child}

The finding showed that the probability of child to be underweight is significantly higher among children who are relatively low age. In particular, as child age increases the probability of being normal in nutrition status among under-five children increases. This implies that as age of the child increases the child has less risk of being underweight. This result is similarity with previous studies of $[17,18]$ which revealed that the risk of being underweight to be not increased as the age of a child increase.

\section{Number of visit by health extension workers}

The regression result revealed that limited access to information on child care and feeding practices was negatively and significantly associated with underweight at $5 \%$ level of significance. This implies that as number of visit with health extension workers increases the child has less risk of being underweight. This result is similarly with 
[21] which revealed that the risk of being underweight to be not increased as the number of visit by health extension workers. Moreover, health extension workers assigned to the study area expected to provide basic knowledge and skill on improved child nutrition for the communities under study. However, the FGD respondents indicated that although there were some attempts made to improve our awareness on how to care and feed our children especially through health extension workers, it was adequate and we have access to get adequate awareness creation and knowledge disseminations conducted through health extension workers to improve our knowledge on child care and breast feeding practices.

\section{Multivariate analysis result stunting}

Family size

The study findings show that the higher family numbers in the household, the greater the chance of being stunted. However, the result is significant only at $1 \%$ significance level. This might be the care and treatment decrease as the family number increases in the household. This finding is consistent with previous studies of which found rather than household family size number was critical and significant determinant in aggravating stunting.

\section{Mother's education}

This study demonstrated that there is significant association between mother's education and stunting. The level of significance increased with level of education. Children whose mother's education level at secondary and college level and above had positively associated with stunting at $1 \%$ significance level. This finding is in line with study results obtained by [22] which found out children from mother which has higher education level attainment was less chance to be being stunted. The direct relationship of mother's education and stunting could be explained that educated mothers are more conscious about their children's health; child nutrition, and they tend to look after their children in a better way.

\section{Monthly income}

Stunting is also influenced by household monthly income with a statistically 5\% significant positive coefficient indicating children from a household with less monthly income has higher likelihood of being stunted compared to those household higher monthly income. This finding is similar to previous studies of [19] showed that the monthly family income was the significantly determinant of stunting.

\section{Birth interval}

The birth interval of child is found to be a statistically significant determinant of stunting. The positive coefficient indicates direct relationship that's as birth interval of child increase the child has probability of being stunted at 5\% significance level. This result is in harmony with finding of which found birth interval was the most important determinants of children nutritional status in Ethiopia.

\section{Currently breast feeding}

Currently breastfeeding showed an effect on being stunted with a statistically $1 \%$ significant negative coefficient indicating children who were not fed breast currently were not likely being stunted compared to those children who fed breast currently. Similar finding was reported by [18] which revealed that the risk of being not currently breastfeeding practice was not associated with stunting. It might be because of stunting is a cumulative effect of long term food deficient, care and exposure to chronic diseases.

\section{Exclusive breastfeeding}

Not exclusive breastfeeding showed an effect on being stunted with a statistically $1 \%$ significant positive coefficient indicating children who were not fed breast exclusively were more likely being stunted compared to those children who fed breast exclusively. Similar finding was reported by [19] not exclusive breastfeeding practice was greatly associated with stunting. 


\section{CONCLUSION}

It was indicated in this study that prevalence of malnutrition manifested by incongruity of weight for age that means underweight is significantly influenced by the number of under five years old children with in a household maternal age, total number of children, birth interval, children's age and the rate of recurrence of advice visit of health extension workers. The study made sure out that the power of infections such as diarrhoea, respiratory diseases, measles, fever, cough and vomiting in rising malnutrition, was decisive factor. Inadequate dietary diversity intake and disease has been found the leading factors that were push children to be more vulnerable to malnutrition. The role of health extension workers in creating awareness on mothers or caretaker towards generating conducive and preventive environment in order to avoid the immediate causes of malnutrition provision of proper foods, health care has not been found at the expected in this study this in turn can contribute to increase the prevalence of malnutrition. Health extension workers should enhance their effort of advising and supervising each household with a special focus on eradicating the prevalence malnutrition and its causes. An introduction and provision of weaning foods for severely malnourished children and children from less income family will have a vital importance by Public Health Centres and other NGOs.

\section{REFERENCES}

1. WHO (2015) Indicators for assessing infant and young child feeding practices: (Part 1) Conclusions of a consensus meeting held in Washington DC, USA.

2. Asfaw M, Wondaferash M, Taha M, et al. (2015) Prevalence of undernutrition and associated factors among children aged between six to fifty nine months in Bule Hora district, South Ethiopia. BMC Public Health 15(1): 38-41.

3. WHO (2016) Strengthening action to improve feeding of infants and young children 6-23 months of age in nutrition and child health programmes: Report of proceedings; Geneva.

4. Rayhan MI, Khan MSH (2006) Factors causing malnutrition among under five children in Bangladesh. Pakistan Journal of Nutrition 5(6): 558-562.

5. Glewwe P and Miguel EA (2007) The impact of child health and nutrition on education in less developed countries. In: Paul Schultz T, John S (Eds.). Hand book of Development Economics. Oxford: Elsevier BV: 3561 -3606.

6. Joosten KF and Hulst JM (2008) Prevalence of malnutrition in pediatric hospital patients. Current Opinion in Pediatrics 20(5): 590-596.

7. Aberash T (2014) Relationship between household food security and nutritional status of children under five in Tigrai: The case of Klteawlaelo, Tigrai, Ethiopia. St. Mary's University.

8. UNICEF (2016) Strategy for improved nutrition of children and women in developing countries.

9. UNICEF (2013) Improving child nutrition: The achievable imperative for global progress, United Nations Children's Fund.

10. UNICEF (2013) Improving child malnutrition. Achievable imperative for global progress. New York.

11. CSA (2011) Ethiopia demographic and health survey (EDHS), Addis Ababa, Ethiopia.

12. Lutter CK, Rivera JA (2003) Nutritional status of infants and young children and characteristics of their diets. The Journal of Nutrition 133(9): 2941S-2949S.

13. Haile A, Amboma TA (2018) Children's nutritional status and its determinants in small towns, Sebeta Hawas district, Oromia, Ethiopia. Journal of Food Science and Nutrition 1(1): 33-47. 
http://www.tridhascholars.org | June-2020

14. CSA (2014) Ethiopia minidemographic and health survey (EDHS), Addis Ababa, Ethiopia.

15. Zewdie T and Abebaw D (2013) Determinants of child malnutrition: empirical evidence from Kombolcha District of Eastern Hararghe Zone, Ethiopia. Quarterly Journal of International Agriculture 52(892-2016-65185): 357-372.

16. Mengistu K, Alemu K, Destaw B (2013) Prevalence of Malnutrition and Associated Factors Among Children Aged 6-59 Months at Hidabu Abote District, North Shewa, Oromia Regional State. Journal of Nutritional Disorders \& Therapy T1: $1-15$.

17. Betebo B, Ejajo T, Alemseged F, et al. (2017) Household food insecurity and its association with nutritional status of children 6-59 months of age in east Badawacho District, south Ethiopia. Journal of environmental and public health: 17.

18. Teshome B, Kogi-Makau W, Getahun Z, et al. (2009) Magnitude and determinants of stunting in children underfive years of age in food surplus region of Ethiopia: the case of West Gojam zone. Ethiopian Journal of Health Development 23(2): 98-106.

19. Roy RK, Matubbar MS, Kamruzzaman M, et al. (2015) Determination of nutritional status of under-five year children employing multiple interrelated contributing factors in southern part of Bangladesh. International Journal of Nutrition and Food Sciences 4(3): 264-272.

20. Takele K (2013) Semi-parametric analysis of children nutritional status in Ethiopia. International Journal of Statistics and Applications 3: 5-141.

21. Liben ML, Abuhay T, Haile Y (2016) Determinants of child malnutrition among agro pastorals in northeastern Ethiopia: A cross-sectional study. Health Science Journal 10(4): 1.

22. Brhane G, Regassa N (2014) Nutritional status of children under five years of age in Shire Indaselassie, North Ethiopia: Examining the prevalence and risk factors. Kontakt 16(3): e161-e170. 